ARTí́CUlo

\title{
Aspectos reproductivos de Mugil curema (Perciformes: Mugilidae) en dos zonas de Baja California Sur, México
}

\author{
Reproductive aspects of Mugil curema (Perciformes: Mugilidae) in two areas of Baja \\ California Sur, México
}

\section{Luis Salgado-Cruz ${ }^{(1}$, Casimiro Quiñonez-Velázquez ${ }^{(1 *}$, Federico A. García- Domínguez $^{1}$, Carlos I. Pérez-Quiñonez ${ }^{1}$ y Valeria Aguilar-Camacho ${ }^{1}$}

${ }^{1}$ Departamento de Pesquerías y Biología Marina, Centro Interdisciplinario de Ciencias Marinas, Instituto Politécnico Nacional, Av. IPN, Col. Playa Palo de Santa Rita, La Paz, Baja California Sur, 23096, México

*Autor corresponsal: cquinone@ipn.mx

\begin{abstract}
The white mullet Mugil curema is one of the main species that exploits the artisanal fishery on the Mexican Pacific coast. Addressing the reproductive aspects of species by fishing area will reduce bias in evaluating the status of their populations. The objective of the present study was to describe the reproductive cycle and estimate some biological parameters of the white mullet in two fishing sites on the coast of Baja California Sur. Monthly, samples from the catch were obtained in Bahía de La Paz (BLP) and Bahía Magdalena (BM), during 2010-2013. Gonadal maturation process was histologically analyzed and the reproductive cycle was described. Gonadosomatic index (GSI), condition factor (CF), hepatosomatic index (HSI), the weight-length relationship and average length of sexual maturity $\left(\mathrm{L}_{50 \%}\right)$ were estimated. The size of the fish varied between 244 and $455 \mathrm{~mm}$ in total length (LT). Females were more abundant $(>70 \%)$, large and heavy than males at both fishing sites. A reproductive pattern was identified with two annual peaks in BLP (March-June and October-November) and one in BM (April-August). A similar pattern of GSI, CF and HSI by sex was identified at both sites. The white mullet showed negative growth allometry, features of total spawning, synchronous gonadal development by groups and an $\mathrm{L}_{50 \%}$ higher in females than males. It is recommended to readjust the closure period by fishing site and based on the $L_{50 \%}$ be cautious in the mesh size of the fishing nets.
\end{abstract}

Key words: Reproductive cycle, La Paz Bay, Magdalena Bay, histological method, average length of sexual maturity

Resumen.- La liseta Mugil curema está entre las principales especies que explota la pesquería artesanal en la costa mexicana del Océano Pacífico. Abordar aspectos reproductivos de las especies por zona de pesca reducirá el sesgo en la evaluación del estado de sus poblaciones. El objetivo del presente estudio fue describir el ciclo reproductivo y estimar algunos parámetros biológicos de la liseta en dos sitios de pesca de la costa de Baja California Sur. Mensualmente, se muestreo la captura de Bahía de La Paz (BLP) y Bahía Magdalena (BM), durante 2010-2013. Se analizó histológicamente la maduración gonadal y se describió el ciclo reproductivo. Se estimaron, el índice gonadosomático (IGS), factor de condición (FC), índice hepatosomático (IHS), la relación peso-longitud y longitud promedio de madurez sexual $\left(\mathrm{L}_{50 \%}\right)$. La longitud total de los peces varió entre 244 y $455 \mathrm{~mm}$. Las hembras fueron más abundantes, grandes y pesadas que los machos en ambos sitios de pesca. Se identificó un patrón reproductivo con dos máximos anuales en BLP (marzo-junio y octubre-noviembre) y uno en BM (abril-agosto). Se identificó un patrón similar del IGS, FC e IHS por sexos en ambos sitios. La liseta mostró alometría negativa en crecimiento, rasgos de desovador total, desarrollo gonadal sincrónico por grupos y la $\mathrm{L}_{50 \%}$ superior en hembras que en machos. Se recomienda reajustar la veda temporal por sitio de pesca y con base en la $\mathrm{L}_{50 \%}$ ser precautorios en el tamaño de la luz de malla de las redes de pesca.

Palabras clave: Ciclo reproductivo, Bahía de La Paz, Bahía Magdalena, método histológico, longitud promedio de madurez sexual

\section{INTRODUCCIÓN}

En peces, la información sobre los aspectos reproductivos y sus variaciones interanuales es clave para conocer la respuesta a la presión del ambiente (Gherard et al. 2013), y de la pesca en aquellos recursos que se encuentran bajo constante aprovechamiento, ya que, para lograr una explotación sostenible, estas respuestas deben evaluarse y comprender sus causas (Stearns 1980). Por tal motivo, se requiere generar conocimiento sobre el ciclo reproductivo de las poblaciones explotadas (Enberg et al. 2012), donde las características de las tácticas reproductivas son fundamentales para comprender las diferencias entre y dentro de las poblaciones, información que reducirá el sesgo en la evaluación de los recursos (Present \& Conover 1992). La descripción de los aspectos reproductivos de peces de importancia comercial, generalmente se ha abordado a partir del análisis macroscópico (Nikolsky 1963) y microscópico (Brown-Peterson et al. 2011, Lowerre-Barbieri et al. 2011) del desarrollo gonadal. Aunque ambos métodos son válidos y se siguen utilizando, el análisis microscópico a partir de la técnica histológica es el de mayor precisión y aprobación actualmente (LowerreBarbieri et al. 2011). 
Las especies de la familia Mugilidae representan uno de los principales recursos en la pesquería artesanal en las regiones templadas y tropicales del mundo (Blaber 1997). En la costa del Pacífico mexicano y Golfo de México esta pesquería explota principalmente dos especies, la liseta Mugil curema Valenciennes, 1836 y la lisa rayada Mugil cephalus Linnaeus, 1758, incluidas en las categorías "Lebrancha" y "Lisa", respectivamente, dentro de la Carta Nacional Pesquera de México (Vasconcelos et al. 1996). La liseta presenta amplia distribución geográfica, habita en lagunas, estuarios y costas ubicadas a lo largo de la franja subtropical. En el Pacífico Oriental se distribuye desde California hasta Chile y en el Atlántico Occidental, desde Cabo Cod, Estados Unidos hasta Brasil, incluido el Golfo de México (Castro-Aguirre 1978). Estos peces pasan la mayor parte de su ciclo biológico en aguas protegidas (Harrison 1995), los adultos forman cardúmenes y migran a la zona pelágica costera, para desovar. Después las postlarvas migran hacia estuarios y lagunas costeras donde permanecen hasta alcanzar la fase adulta (Trape et al. 2009). En el caso del Pacífico mexicano, sus volúmenes de captura han superado las $12.000 \mathrm{t}$ anuales durante la última década (AEP 2017), actualmente más del 75\% proviene de las costas del Golfo de California, donde la pesca de M. curema está regulada por la Norma Oficial Mexicana NOM016-PESC-1994 actualizada en 2015 (DOF 2015) ${ }^{1}$ y por la Carta Nacional Pesquera, que establece la talla mínima de captura de $28 \mathrm{~cm}$ LT y el periodo de veda del 1 de abril al 30 de junio.

Se han realizado diversos estudios en costas mexicanas que abordan aspectos reproductivos de la liseta $M$. curema (Yáñez-Arancibia 1976, Villaseñor \& González 1990², Lucano-Ramírez \& Michel-Morfin 1997, Cabral-Solís 1999, Ibáñez \& Gallardo-Cabello 2004, Ibáñez \& GutiérrezBenítez 2004, Cabral-Solís et al. 2010, Ibáñez \& Colín 2014, Ruíz-Ramírez et al. 2017). Sin embargo, la mayor parte de estos trabajos se han realizado para el norte del Golfo de México y al sur del Golfo de California; por tal motivo, es necesario generar información referente a la reproducción de esta especie en zonas no estudiadas de ambos litorales, sobre todo en aquellas donde este recurso se captura frecuentemente, tal como sucede en gran parte del noroeste del Pacífico mexicano, donde la normativa que regula la captura de este recurso, no está basada en información propia de la región. El presente trabajo es el primero en abordar aspectos de la biología reproductiva de la liseta en Baja California Sur (BCS), cuyo objetivo fue describir el ciclo reproductivo y estimar algunos parámetros a partir de un análisis microscópico del desarrollo gonadal en dos localidades con marcadas diferencias ambientales, Bahía de La Paz en la costa sureste y Bahía Magdalena en la costa suroeste de BCS, para obtener información importante para evaluar el estado de las poblaciones y contribuir a la integración de acciones para una adecuada administración, de manera tal que los escenarios de pesca estén fundamentados en información local y no a partir de una generalización, como se ha llevado a cabo con la mayoría de las especies explotadas.

\section{MATERIALES Y MÉTODOS}

\section{Área de ESTUdio}

La Bahía de La Paz (BLP) se ubica en la costa este de la Península de Baja California a $200 \mathrm{~km}$ de la boca del Golfo de California (GC) $\left(24,1-24,8^{\circ} \mathrm{N} ; 110,2-110,8^{\circ} \mathrm{O}\right)$ (Fig. 1). El ciclo anual de la temperatura superficial del mar (TSM) presenta dos estaciones bien definidas, invierno-primavera (21-24 ${ }^{\circ} \mathrm{C}$ ), y verano-otoño $\left(27-31{ }^{\circ} \mathrm{C}\right.$ ) (Bernal et al. 2001). Bahía Magdalena (BM) es un sistema lagunar que se encuentra en la costa occidental de Baja California Sur $\left(24^{\circ} 15^{\prime}-25^{\circ} 20^{\prime} \mathrm{N} ; 111^{\circ} 30^{\prime}-112^{\circ} 15^{\prime} \mathrm{O}\right)$ (Fig. 1). El promedio de la TSM, en el mes más frío del año (mayo) es de 17,8 ${ }^{\circ} \mathrm{C}$ y en el más cálido (agosto) de $29^{\circ} \mathrm{C}$ (Funes-Rodríguez et al. 2007).

\footnotetext{
${ }^{1}$ Diario Oficial de la Federación (DOF). 2015. Norma Oficial Mexicana NOM-016-SAG/PESC-2014. Para regular la pesca de lisa y liseta o lebrancha en aguas de jurisdicción federal del Golfo de México y Mar Caribe, así como del Océano Pacífico, incluyendo el Golfo de California. Ciudad de México, México, 4 pp.

${ }^{2}$ Villaseñor R \& A González. 1990. Aspectos reproductivos de lisa blanca Mugil curema (Valenciennes 1838 Pisces: Mugilidae) en aguas estuarinas marinas de San Blas, Nayarit, México. II Congreso de Ciencias Marinas. La Habana, Cuba, p. 233 [resumen].
} 


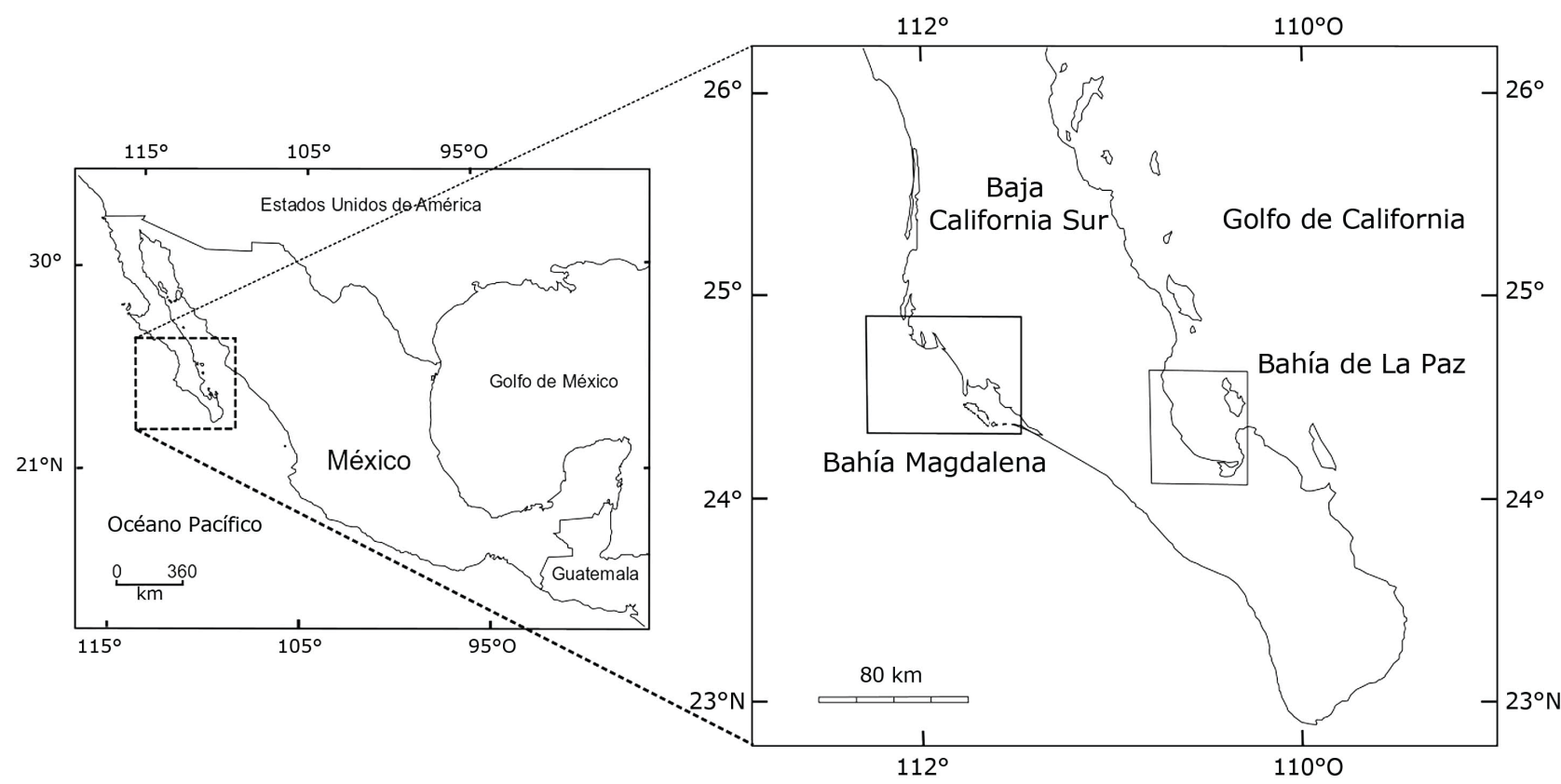

Figura 1. Ubicación geográfica del área de estudio, zonas de muestreo en recuadros se localizan en ambas costas de Baja California Sur / Geographic location of the study area, boxed sampling areas are located on both coasts of Baja California Sur

\section{Muestreo}

A partir de la captura de la flota artesanal se recolectaron 690 organismos en BLP y 865 en BM, desde el 2010 a 2013. En cada mes de manera aleatoria se seleccionaron algunas embarcaciones y se obtuvo información de hasta 40 organismos, buscando representar la estructura de tallas de la captura. La identificación de los peces se realizó con base en el trabajo de Ibáñez \& Gallardo-Cabello (2005). A cada organismo se le registró la longitud total $(\mathrm{LT} \pm 0,1 \mathrm{~cm})$, peso total y eviscerado (PT y PE, respectivamente $\pm 0,1 \mathrm{~g}$ ), se extrajeron las gónadas e hígado y se pesaron ( $\mathrm{PG}$ y $\mathrm{PH} \pm 0,1$ $\mathrm{g}$, respectivamente). El sexo y estadio de madurez se asignó por apreciación visual de acuerdo con Marin et al. (2003). Las gónadas se fijaron en formol al 10\% preparado en agua de mar. Una sección (alrededor de $1 \mathrm{~cm}$ de ancho) del lóbulo izquierdo fue extraída para su procesamiento de acuerdo con la técnica histológica: deshidratación en alcohol, inclusión en parafina, cortes con micrótomo ( 3 a $5 \mu \mathrm{m}$ de grosor), y tinción con hematoxilina-eosina. Para asignar la fase de desarrollo cada laminilla fue evaluada por dos lectores de manera independiente, siguiendo una modificación de la escala y estandarización de términos propuesta por BrownPeterson et al. (2011) y Lowerre-Barbieri et al. (2011) (Tabla 1). Se seleccionaron algunas gónadas al azar para examinar distintas secciones transversales de todo el lóbulo sin detectar diferencias en estas secciones en el desarrollo de la gametogénesis para esta especie. En el caso de las hembras, se tomaron mediciones del diámetro de aproximadamente 200 células por cada fase de desarrollo ovárico (en promedio 30 células por ovario), sólo se midieron aquellas células que presentaron un núcleo definido.

\section{ESTRUCTURA DE TALLAS Y RELACIÓN PESO-LONGITUD}

Se analizó la estructura de tallas por mes, agrupando los organismos en intervalos de $10 \mathrm{~mm}$. Las diferencias en longitud promedio entre sexos y localidades se evaluaron mediante la prueba Mann-Whitney (U) usando el programa

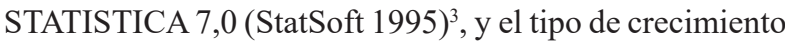
a partir de la relación potencial peso-longitud (PT-LT):

$$
P T=a \cdot L T^{b}
$$

donde, PT es el peso total estimado, LT longitud total del organismo, $a$ y $b$ son los coeficientes de la ecuación (intercepto y exponente, respectivamente). Posteriormente se comprobó la hipótesis de isometría $b=3$ mediante una prueba $t$ (Pauly \& Munro 1984). Las diferencias en el valor de la pendiente (b) entre sexos y localidades se determinaron mediante un análisis de covarianza (ANCOVA).

\footnotetext{
${ }^{3}$ StatSoft. 1995. STATISTICA (data analysis software system), version
} 7.0. <www.statsoft.com> 
Tabla 1. Criterio histológico para asignar el estadio reproductivo una vez ocurrida la diferenciación sexual de Mugil curema. Modificado de LowerreBarbieri et al. (2011) / Histological criteria to assign the reproductive stage after Mugil curema sexual differentiation has occurred. Modified from Lowerre-Barbieri et al. (2011)

\begin{tabular}{|c|c|c|}
\hline \multirow{2}{*}{ Estadio de desarrollo } & \multicolumn{2}{|c|}{ Características histológicas } \\
\hline & Hembras $(\mathrm{H})$ & Machos (M) \\
\hline Inmaduro (I) & $\begin{array}{l}\text { Solo ovogonias }(\mathrm{Og}) \text { y ovocitos en } \\
\text { crecimiento primario, en fase } \\
\text { perinucleolar inicial }(\mathrm{Pi}) \text { y final }(\mathrm{Pf}) \text {. } \\
\text { Sin atresia y pared ovárica delgada, } \\
\text { poco espacio entre los ovocitos. }\end{array}$ & $\begin{array}{l}\text { Sólo presencia de } \\
\text { espermatogonias }(\mathrm{Sg}) \text { y poco } \\
\text { o ningún desarrollo de } \\
\text { espermatocitos. }\end{array}$ \\
\hline $\begin{array}{l}\text { H: Desarrollo (II) } \\
\text { M: Desarrollo temprano (II) }\end{array}$ & $\begin{array}{l}\text { Presencia de ovocitos en la fase de } \\
\text { alvéolos corticales (AC) y vitelogénesis } \\
\text { primaria (Vtg1) generalmente los } \\
\text { ovocitos alcanzan un tamaño de } 180 \mu \mathrm{m} \\
\text { y continúan aumentando de tamaño. No } \\
\text { hay presencia de vitelogenesis terciaria } \\
\text { (Vtg3). }\end{array}$ & $\begin{array}{l}\text { Presencia de espermatocistos } \\
\text { con } \mathrm{Sg} \text {, espermatocitos } \\
\text { primarios (Ep) y secundarios } \\
\text { (Es). }\end{array}$ \\
\hline $\begin{array}{l}\text { H: Maduro (III) } \\
\text { M: Desarrollo tardío (III) }\end{array}$ & $\begin{array}{l}\text { Ovario con Ovocitos en vitelogenesis } \\
\text { secundaria (Vtg2), terciaria (Vtg3), y en } \\
\text { la fase de migración de la vesícula } \\
\text { germina (Mvg). Presencia de algunas } \\
\text { células en proceso de atresia. }\end{array}$ & $\begin{array}{l}\text { Presencia de todas las fases } \\
\text { de la espermatogénesis Ep, } \\
\text { Es, espermátida (Et) e incluso } \\
\text { espermatozoides (Ez) en los } \\
\text { espermatocistos. Estos } \\
\text { últimos aún no se encuentran } \\
\text { en el conducto deferente. }\end{array}$ \\
\hline $\begin{array}{l}\text { H: Desove (IV) } \\
\text { M: Capacidad de desove (IV) }\end{array}$ & $\begin{array}{l}\text { Mayor parte de los ovocitos en Pi o AC, } \\
\text { presencia de atresia y folículos } \\
\text { postovulatorios (Fpo). }\end{array}$ & $\begin{array}{l}\text { Acumulación de Ez en } \\
\text { espermatocistos y en } \\
\text { conducto deferente. Poca o } \\
\text { nula presencia de } \\
\text { espermatogénesis. }\end{array}$ \\
\hline
\end{tabular}

\section{ASPECTOS REPRODUCTIVOS}

Se describió el patrón reproductivo y el análisis de los cambios en la madurez gonadal durante un ciclo anual, a partir de cinco métodos complementarios para ambos sexos por separado: (1) La apreciación visual macroscópica de las gónadas utilizando una escala morfocromática (Marin et al. 2003); (2) análisis microscópico del desarrollo gonadal; (3) índice gonadosomático (IGS), como indicador de los cambios en la relación porcentual entre el peso del pez y el peso de las gónadas (Lucano-Ramírez et al. 2014); (4) factor de condición (FC), bajo el supuesto de que existe una relación inversa con el IGS, que generalmente coincide con el periodo de madurez gonádica (SánchezCárdenas et al. 2007) y (5) índice hepatosomático (IHS), a partir de que el número y tamaño de los hepatocitos (consecuentemente el peso del hígado) en el caso de las hembras, está relacionado con la vitelogénesis (Albieri et al. 2009). Los índices anteriores se calcularon a partir de las siguientes ecuaciones (Rodríguez-Gutiérrez 1992):

$$
\begin{gathered}
I G S=\left[\frac{P_{G}}{P_{E}-P_{G}}\right] \cdot 100 \\
F C=\left[\frac{P_{E}}{L T^{b}}\right] \cdot 100 \\
I H S=\left[\frac{P_{H}}{P_{E}}\right] \cdot 100
\end{gathered}
$$

donde, $b$ es el valor de la pendiente de la relación potencial entre PT y LT. La prueba de normalidad,
Shapiro-Wilks (STATISTICA 7,0) ${ }^{3}$, fue significativa en todos los casos (IGS, IHS, y FC: $P<0,05$ ); para evaluar los cambios mensuales en los valores de cada índice, se utilizó un ANOVA no paramétrico (Kruskal-Wallis). La relación mensual entre el FC, el IGS y el IHS por sexos fue estimada a partir de la prueba de correlación por rangos de Spearman $\left(\mathrm{r}_{\mathrm{s}}\right)$. Para comparar y determinar si la proporción sexual difiere de la esperada 1:1, se estimó la proporción sexual total, mensual y por grupo de talla mediante la prueba Chi cuadrada $\chi^{2}$ con corrección por continuidad de Yates (Zar 2010):

$$
X_{\text {Yates }}^{2}=\sum\left(\frac{\left(\left|f_{i}-f_{\text {iesp }}\right|-0,5\right)^{2}}{f_{\text {iesp }}}\right)
$$

donde, $f_{i}$ es la frecuencia de machos o hembras observada y $f_{\text {iesp }}$ la esperada.

Se estimó la longitud a la cual el 50\% de los individuos dentro de un intervalo de talla han alcanzado la madurez sexual $\left(\mathrm{L}_{50 \%}\right)$, ajustando un modelo logístico (Lysack 1980) a la proporción de organismos maduros por dicho intervalo $(10 \mathrm{~mm})$ :

$$
P_{i}=\frac{1}{\left(1+e^{\left[-r\left(L T_{i}-L_{50 \%}\right)\right]}\right)}
$$

donde, $P_{i}$ es la proporción de organismos maduros en el intervalo de talla $i, L T_{i}$ es la clase de talla del intervalo $i, r$ representa la velocidad a la que se alcanza la madurez sexual y $\mathrm{L}_{50 \%}$ es la talla a la cual el $50 \%$ de $\operatorname{los}$ organismos de la población son sexualmente maduros. 
El ajuste del modelo se realizó minimizando la función de verosimilitud objetiva con el algoritmo de búsqueda directa de Newton (Kutner et al. 2004, pp. 515-518), según la siguiente ecuación que asume una distribución binomial (Jacob-Cervantes \& Aguirre-Villaseñor 2014).

$$
-L n L=-\sum_{i=1}^{n}\left[m i \cdot \operatorname{Ln}\left(\frac{P_{i}}{1-P_{i}}\right)+n i \cdot \operatorname{Ln}\left(1-P_{i}\right)+\operatorname{Ln}\left(\begin{array}{c}
n_{i} \\
m_{i}
\end{array}\right)\right]
$$

donde $\mathrm{n}_{i}$ es el número total de organismos dentro de la clase de talla $i$ y $m_{i}$ es el número de organismos maduros dentro de la clase de talla $i$.

siendo:

$$
\left(\begin{array}{c}
n_{i} \\
m_{i}
\end{array}\right)=\frac{n_{i} !}{\left(\left(n_{i}-m_{i}\right) ! \cdot m_{i}\right)}
$$

Este parámetro se calculó para cada localidad y sexo, las diferencias estadísticas entre estos valores fueron evaluadas a partir del análisis de los residuos de la suma de cuadrados (ARSS) (Zar 2010). Los intervalos de confianza (al 95\%) de la $\mathrm{L}_{50 \%}$ se estimaron a partir del cálculo del perfil de verosimilitud suponiendo una distribución $\chi^{2}$, con $m$ grados de libertad (Polacheck et al. 1993).

\section{RESUltados}

\section{EstruCtura de TALlas y PESOS}

En el total de organismos examinados, la longitud total (LT) varió entre 254 y $405 \mathrm{~mm}$ en BLP y de 244 a $455 \mathrm{~mm}$ en BM, y el peso total (PT) de 139 a 595 g y de 133 a 901 $\mathrm{g}$, respectivamente. Los peces de BM (330,1 mm de LT y $326,4 \mathrm{~g}$ de $\mathrm{PT}$ ) fueron en promedio más grandes y pesados (Prueba U: $\mathrm{Z}=-5,35, P<0,05)$ que en $\operatorname{BLP}(323,7 \mathrm{~mm}$ de LT y 309,2 g de PT). En ambas localidades las hembras (H) conformaron la mayor parte de la muestra $(84 \%$ en BLP y 74\% BM) y presentaron tallas y pesos mayores que los machos (M), en BLP (U: $\mathrm{Z}=-7,87, P<0,05)$ : 326,6 (H) y 303,1 (M) mm de LT y 316,2 (H) y 262,7 g (M) de PT, y en BM (BM U: $Z=-10,15, P<0,05): 336,5(\mathrm{H})$ y 312,3 (M) mm de LT y 343,4 (H) y 280,6 g (M) de PT. En BLP las mayores frecuencias $(n>15)$ en los machos se presentaron a los 295 y $305 \mathrm{~mm}$ de LT; y en las hembras (n > 100) a los 315 y 335 mm de LT (Fig. 2). En BM las mayores frecuencias en machos $(n>20)$ fueron a los 315 y $325 \mathrm{~mm}$ de LT y en hembras $(\mathrm{n}>80)$ a los 335 y 345 mm de LT (Fig. 2).

a)

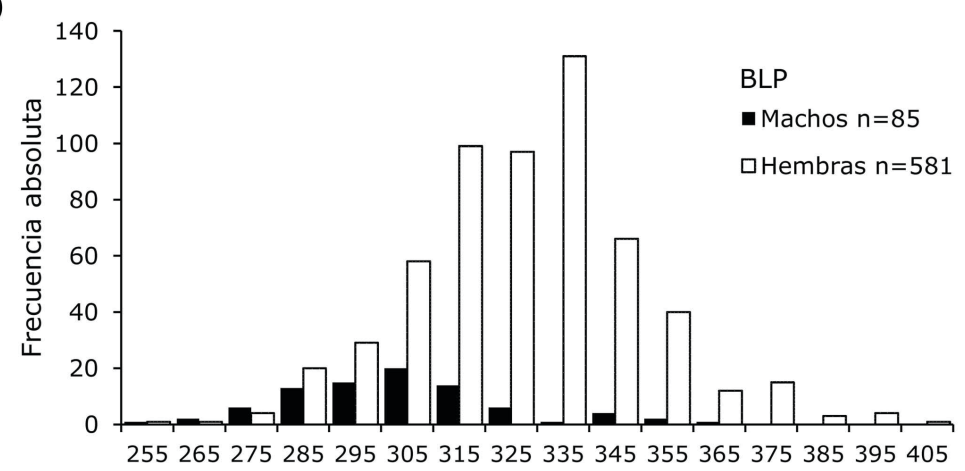

b)

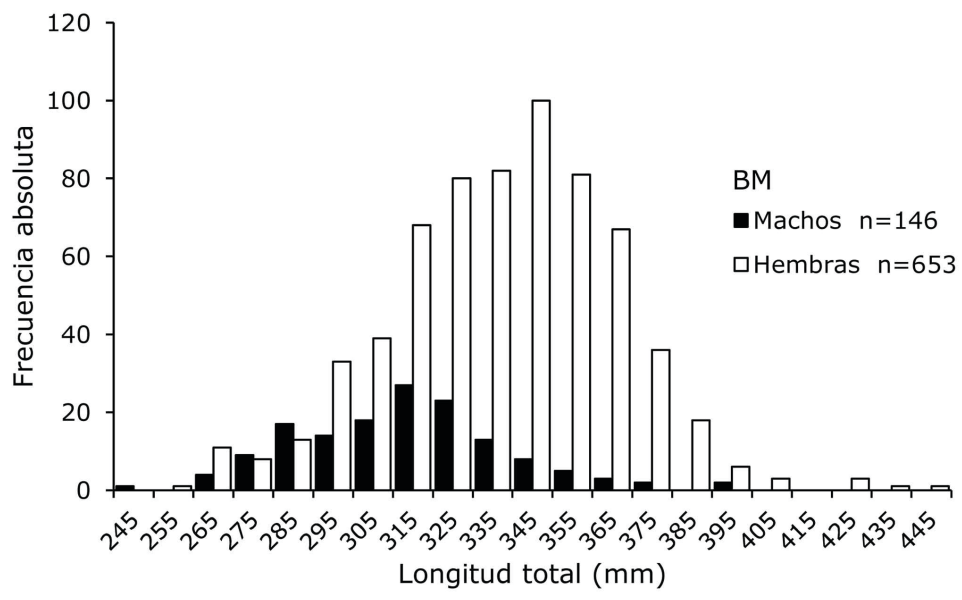

Figura 2. Distribución de frecuencia de tallas para hembras y machos de Mugil curema en a) Bahía de La Paz (BLP) y b) Bahía Magdalena (BM) / Length frequency distribution for females and males of Mugil curema from a) Bahía de La Paz (BLP) and b) Bahía Magdalena (BM) 


\section{RELACIÓN PESO-LONGITUD}

Se identificó una alta correspondencia entre la LT y el PT, tanto para BLP como para BM $\left(\mathrm{R}^{2}>0,80\right)$. En ambas localidades el crecimiento de la liseta presentó alometría negativa ( $b=2,4$ en BLP y $b=2,6$ en BM), mayor incremento en longitud que en peso (Fig. 3), no se detectaron diferencias significativas en el valor de la pendiente (b) de la relación LT-PT entre localidades (ANCOVA: $\left.\mathrm{F}_{(1,1551)}=3,1, P=0,07\right)$, ni entre sexos en cada localidad (ANCOVA: $\mathrm{F}_{(1,655)}=1,56, P=0,21 \mathrm{BLP}_{\mathrm{y}} \mathrm{F}_{(1,804)}=$ $3,36, P=0,067 \mathrm{BM})$.

\section{Características del ovario}

Se identificaron 4 estadios de desarrollo gonadal. Los ovarios en estadio inmaduro (I) se caracterizaron por ser dos lóbulos alargados y delgados de longitud similar, de coloración transparente a amarillo, con forma semicircular y una pequeña arteria dispuesta longitudinalmente. Microscópicamente los ovarios presentan ovogonias (Og) y ovocitos en crecimiento primario con un diámetro que va de 38,5 a 82,0 $\mu \mathrm{m}(62,1 \pm 10,8 \mu \mathrm{m}$, promedio y desviación estándar respectivamente), en las fases perinucleolar inicial (Opi) y final (Opf) (Fig. 4a). En el estadio en desarrollo (II) los lóbulos incrementaron su tamaño y su forma

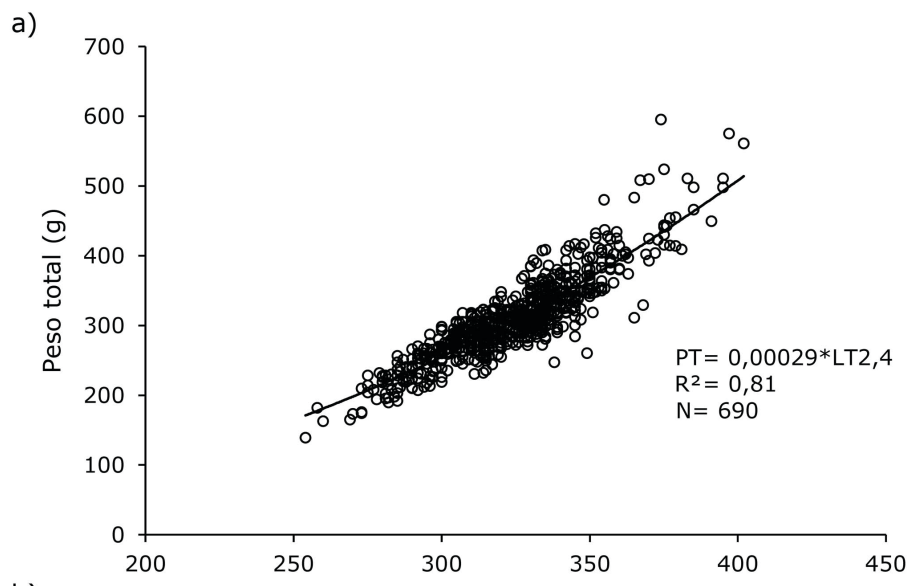

b)

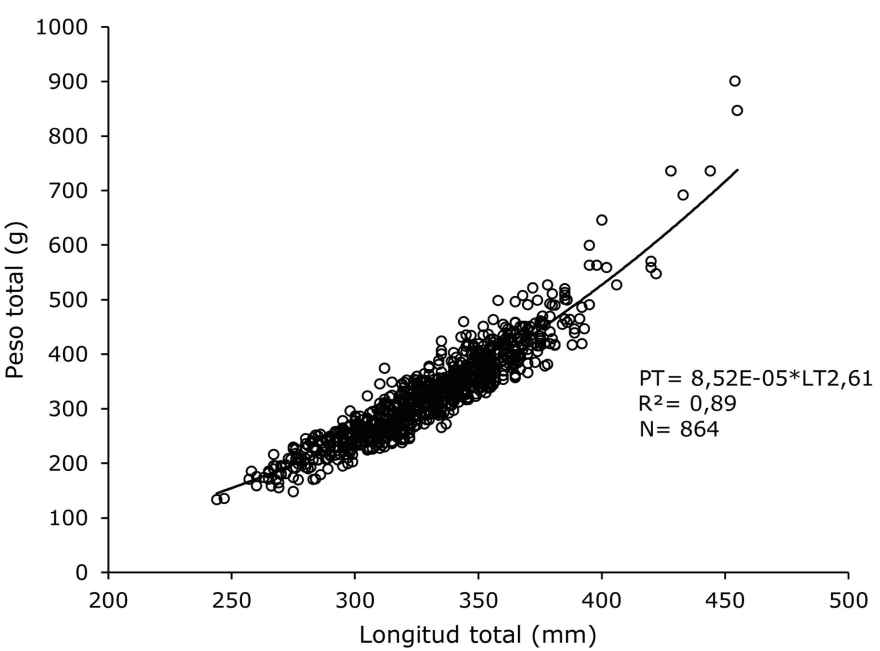

Figura 3. Relación peso-longitud de Mugil curema por sitio de muestreo. a) Bahía de La Paz y b) Bahía Magdalena / Mugil curema length-weight relationship by sampling site. a) Bahía de La Paz and b) Bahía Magdalena 

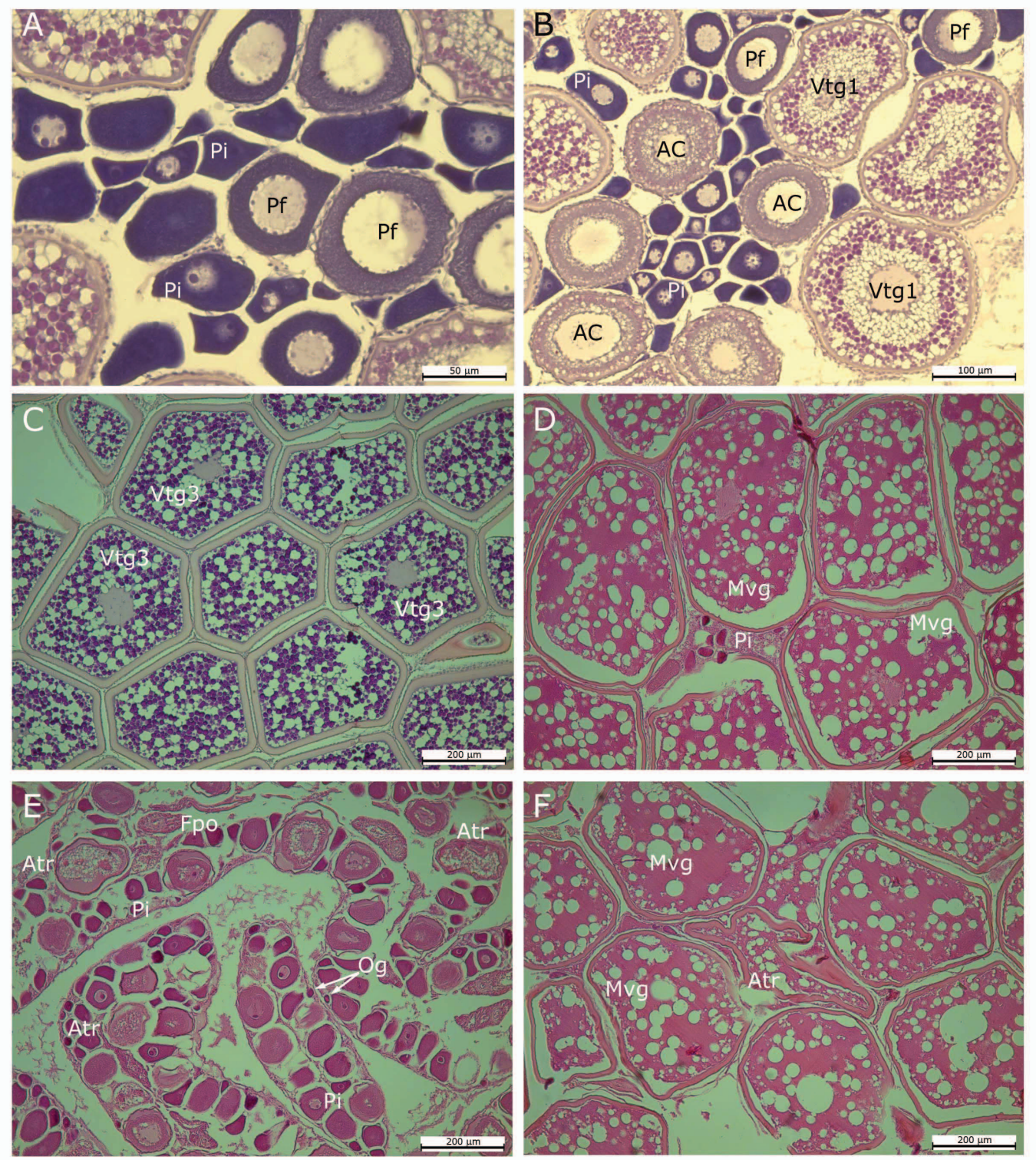

Figura 4. Proceso de maduración del ovario de Mugil curema. A) Ovario inmaduro con células en crecimiento primario, en la fase de perinucleolar inicial (Pi) y final (Pf); B) Ovario en desarrollo con células en la fase de alveolos corticales (AC) y vitelogénesis inicial (Vtg1); C, D) Ovario maduro con células en la fase de vitelogénesis terciaria (Vtg3) y migración de la vesícula germinal (Mvg); E-F) Células en fase AC y Mvg en proceso atresia (Atr). Og: Ovogonia / Maturation process of the ovary of Mugil curema. A) Immature ovary with cells in primary growth, in the initial (Pi) and final (Pf) perinucleolar phase; B) Developing ovary with cells in the cortical alveoli phase (AC) and initial Vitellogenesis (Vtg1); C, D) Mature ovary with cells in the phase of tertiary vitellogenesis (Vtg3) and migration of the germinal vesicle (Mvg); E-F) Cells in AC phase and Mvg in atresia process (Atr). Og: oogonia

redondeada es evidente, el color amarillo es más intenso y se distingue la presencia de vasos sanguíneos paralelos a la arteria. Pueden identificarse histológicamente ovocitos en la fase de alveolos corticales (AC) con diámetro de 85,9 a $124,5 \mu \mathrm{m}(106 \pm 11,9 \mu \mathrm{m})$ y ovocitos que inician con el proceso de la vitelogénesis (Vtg1) con diámetro de 141,6 a 232,1 $\mu \mathrm{m}(186,7 \pm 22,17 \mu \mathrm{m})$ (Fig. 4b). La presencia de AC es el marcador definitivo que da pauta al inicio del periodo reproductivo. Los ovarios en estadio de madurez (III) se identificaron macroscópicamente por un incremento considerable en el tamaño de los lóbulos. Presentaron color amarillo pálido, aspecto liso, turgente y forma redondeada, fue posible distinguir a simple vista los ovocitos (en forma de gránulos). Microscópicamente se observaron algunos ovocitos en vitelogénesis secundaria (Vtg2) con diámetro de 181,1 a $377,1 \mu \mathrm{m}(277,7 \pm 41 \mu \mathrm{m})$, la mayor parte en vitelogénesis terciaria $(\mathrm{Vtg} 3)$ diámetro de 245,2 a 405,4 (354,6 $\pm 34,7 \mu \mathrm{m})$ (Fig. 4c) y algunos en la fase de migración de la vesícula germinal (Mvg) con un diámetro de 405,9 a 656,5 $\mu \mathrm{m}(472,5 \pm 56,8 \mu \mathrm{m})$ (Fig. 4d). En el estadio desovado (IV) los ovarios presentan lóbulos de menor tamaño que el estadio anterior, apariencia arrugada 
y de coloración rojiza a púrpura. Histológicamente este estadio se caracterizó por presentar ovocitos en crecimiento primario, algunos en AC y folículos que contenían al ovocito antes de ser liberado (folículos postovulatorios, Fpo). En ambas localidades se identificaron ovarios con células en proceso de atresia folicular (Atr), principalmente en ovocitos característicos del estadio en desarrollo (Fig. 4e) y madurez (Fig. 4f).

\section{Características del testículo}

A partir de las características morfológicas de los testículos el proceso de maduración se dividió en cuatro estadios de madurez. En el estadio I la coloración de los testículos varía de gris a transparente, los lóbulos son alargados y delgados con paredes lisas. Microscópicamente presentaron sólo espermatogonias $(\mathrm{Sg})$ en el epitelio germinal (GE) (Fig. 5a). En el estadio II, se incrementa el tamaño de los lóbulos que se observan de forma triangular en un corte transversal. También se observó bien diferenciada la arteria longitudinal. Microscópicamente el testículo se compone por cistos (Ec) conformados por $\mathrm{Sg}$, espermatocitos primarios (Ep), espermatocitos secundarios (Es) y espermátidas (Et) (Fig. 5b). Conforme continuó el desarrollo del testículo (estadio III o desarrollo tardío), los lóbulos incrementaron considerablemente su tamaño y peso, y su coloración blanca se hizo más intensa. En contraste con el estadio anterior, los Ec contienen todas las etapas de la espermatogénesis, Sg, Ep, Es, Et y espermatozoides (Ez) (Fig. 5c); sin embargo, la liberación de Ez de los cistos hacia los conductos no ocurre aún. El estadio IV se caracterizó por lóbulos turgentes y color blanco pálido, de gran tamaño y forma triangular. La arteria longitudinal en cada lóbulo es muy evidente. Microscópicamente se identificaron Ez acumulados dentro de los Ec y en los conductos deferentes (Cd) (Fig. 5d).
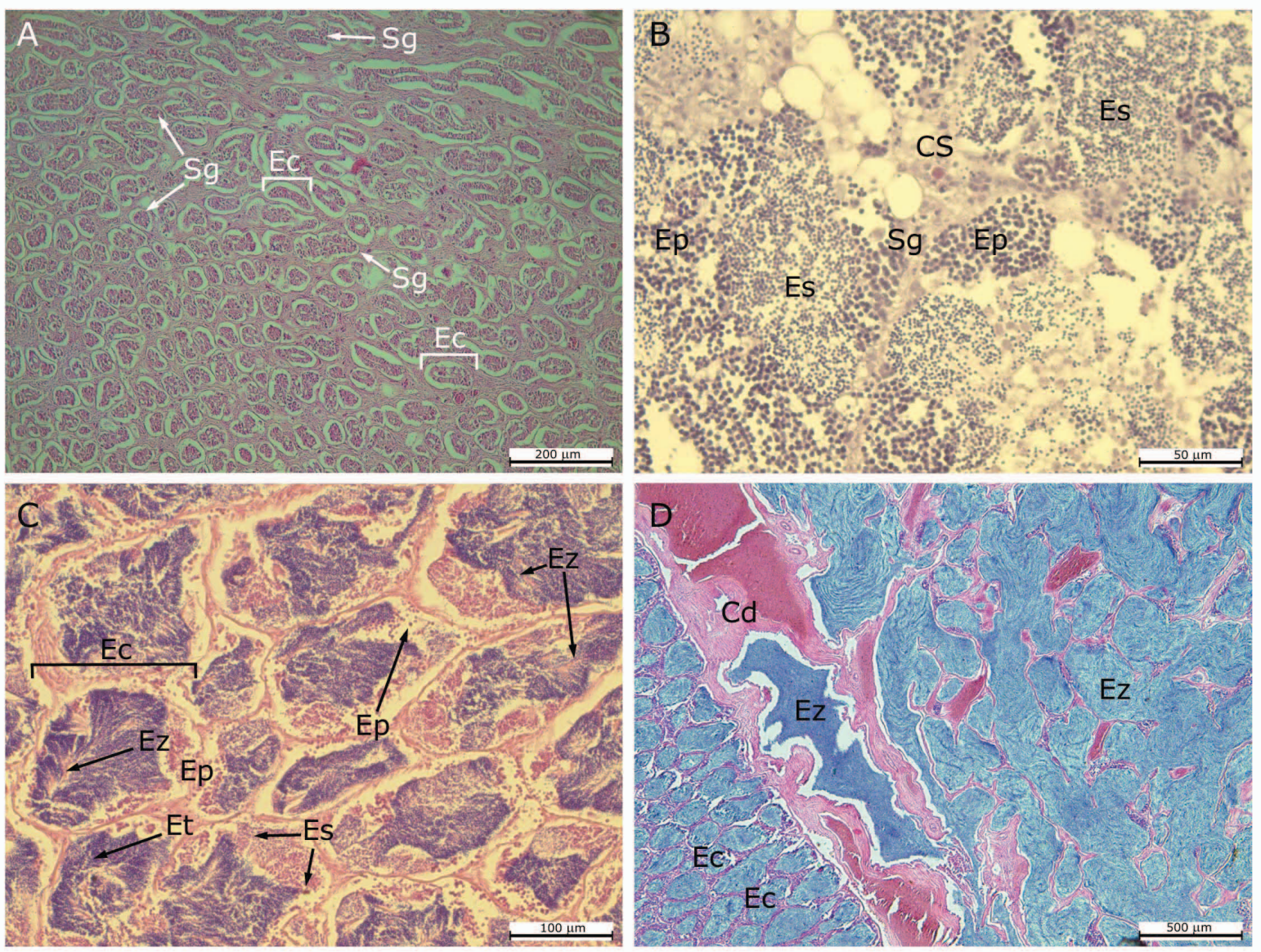

Figura 5. Proceso de maduración del testículo de Mugil curema. A) Testículo inmaduro con células en la fase de espermatogonias (Sg); B) Testículo en estadio de desarrollo temprano con células en la fase de $\mathrm{Sg}$, espermatocito primario (Ep) y espermatocito secundario (Es); C) Testículo en desarrollo tardío con todas las fases celulares de la espermatogénesis Sg, Ep, Es, espermátida (Et) y espermatozoides (Ez); D) Testículo capaz de desovar (IV) con Ez acumulados en espermatocistos (Ec) y en los conductos deferentes (Cd). Células de Sertoli (CS) / Testicular differentiation in Mugil curema. A) Immature testicle with cells in the spermatogonial phase (Sg); B) Testis in early development stage with cells in the Sg phase, primary spermatocyte (Ep) and secondary spermatocyte (Es); C) Late developing testis with all the cellular phases of the spermatogenesis Sg, Ep, Es, spermatids (Et) and spermatozoa (Ez); D) Testicle capable of spawning (IV) with Ez accumulated in spermatocysts (EC) and in the vas deferens (Cd). Sertoli cells (CS) 


\section{ACTIVIDAd REPRODUCTIVA}

En ambas zonas se detectaron peces en estadios III y IV durante la mayor parte del año $(\mathrm{n}=231$ en BLP y $\mathrm{n}=$ 204 en BM), sin embargo, el patrón reproductivo anual fue distinto en las dos localidades. Se identificaron dos periodos reproductivos en BLP, el primero de mayor duración y porcentaje (marzo-junio, 49\%) que el segundo (octubre-noviembre, 22\%) (Fig. 6). En BM se presentó un solo periodo reproductivo durante el año, con mayor amplitud e intensidad (abril-agosto, 82\%) que en BLP (Fig. 6). La temporada del año en la que se registró menor frecuencia de organismos maduros fue durante septiembre y diciembre-febrero en BLP, y septiembre-marzo en BM.

\section{ÍNDICE GONADOSOMÁTICO}

Se detectaron diferencias significativas en los valores mensuales del IGS en ambas localidades para ambos sexos (Kruskal-Wallis ANOVA: $\mathrm{H}_{(11,82)}=23,14, P<0,05$ para machos y $\mathrm{H}_{(11,574)}=62,7, P<0,05$ para hembras en BLP; $\mathrm{y}_{(10,162)}=77,09, P<0,05$ para machos $\mathrm{y}_{(10,640)}=298,8$, $P<0,05$ para hembras en BM), cuyo patrón mostró dos máximos (junio-julio y octubre-noviembre) en BLP; y uno en mayo-agosto en BM (Fig. 7). En ambas localidades se detectó una correlación positiva significativa $\left(\mathrm{r}_{\mathrm{s}}=0,6, P<\right.$ 0,05 , en BLP y $\mathrm{r}_{\mathrm{s}}=0,76, P<0,05$, en $\mathrm{BM}$ ) entre las series, sugiriendo sincronía en la maduración entre machos y hembras.
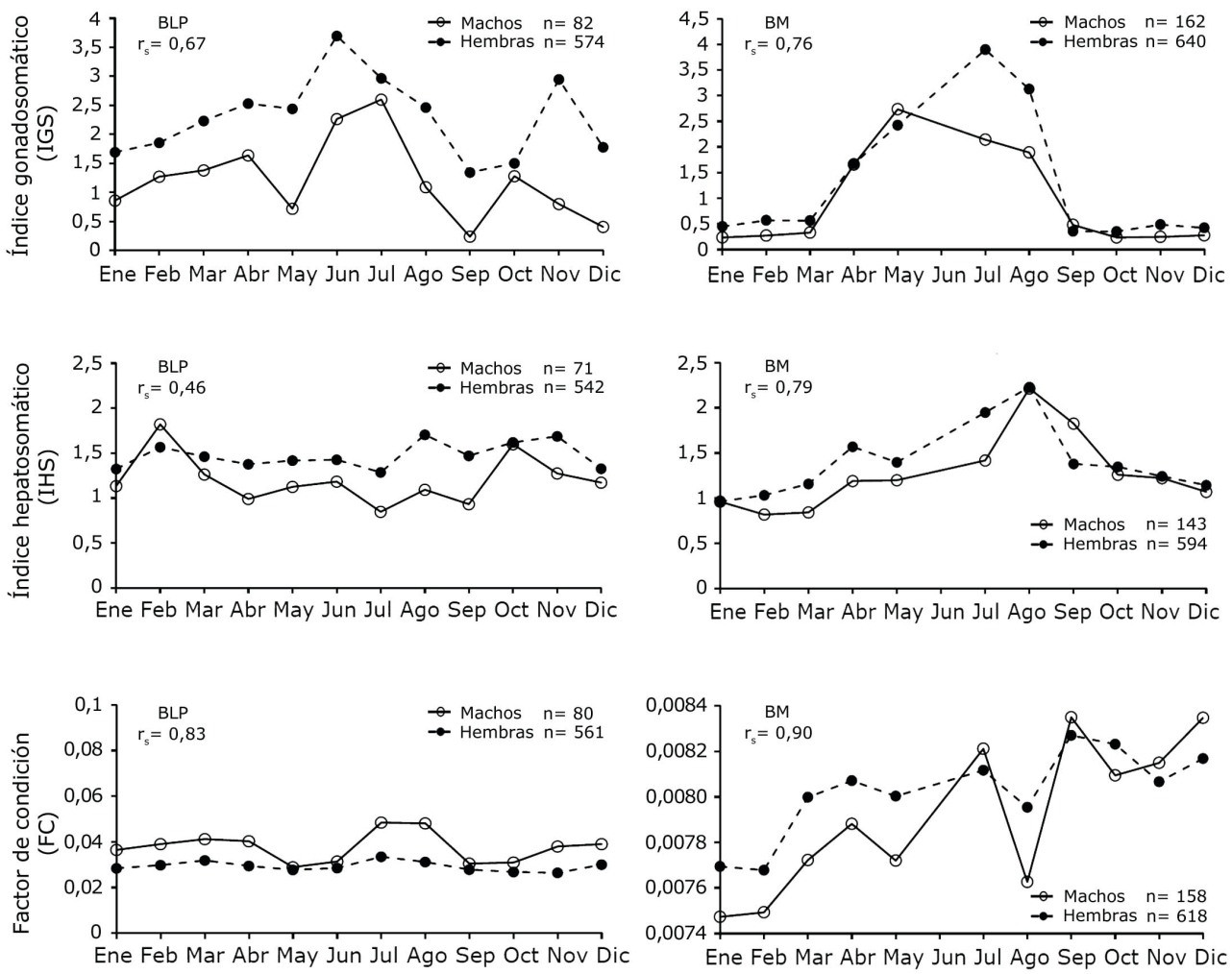

Figura 7. Variación mensual del índice gonadosomático (IGS), índice hepatosomático (IHS) y factor de condición (FC) en hembras y machos de Mugil curema en Bahía de La Paz (BLP) y Bahía Magdalena (BM). rs: valor de la correlación de Spearman / Monthly variation of the gonadosomatic index (IGS), hepatosomatic index (IHS) and condition factor (FC) for Mugil curema females and males in Bahía de La Paz (BLP) and Bahía Magdalena (BM). rs: Spearman correlation value 


\section{FACTOR DE CONDICIÓN}

Se identificó un cambio significativo en los promedios por mes del FC en ambas localidades y sexos (Kruskal-Wallis ANOVA: $\mathrm{H}_{(11,80)}=18,25 ; P<0,05$ para machos $\mathrm{y}_{(11,561)}=$ 36,96; $P<0,05$ para hembras en BLP y $\mathrm{H}_{(10,158)}=38,17 ; P<$ 0,05 para machos y $\mathrm{H}_{(10,618)}=46,84 ; P<0,05$ para hembras en $\mathrm{BM}$ ), con valores máximos en BLP durante julioagosto, y mínimos en mayo-junio. En BM la tendencia fue ascendente, los máximos durante la segunda mitad del año (Fig. 7). Las hembras y machos presentaron sincronía en la tendencia mensual del FC $\left(r_{s}=0,83\right.$ en BLP y $r_{s}=0,9$ en BM).

\section{Proporción SEXUAL}

Para el total de organismos analizados en BLP la proporción sexual fue de $1,0 \mathrm{H}: 0,02 \mathrm{M}\left(\chi^{2}=372, P<0,001\right)$, y en BM de $1,0 \mathrm{H}: 0,1 \mathrm{M}\left(\chi^{2}=275, P<0,001\right)$, en ambos sitios significativamente distinta de la esperada 1:1. Durante la mayor parte de los meses muestreados la proporción de hembras fue significativamente mayor que la de machos en ambas localidades. En BM, sólo durante septiembre los machos fueron más abundantes que las hembras, sin embargo, dicha proporción no fue significativamente distinta de la esperada $\left(\chi^{2}=0,26, P>0,05\right)$. En el análisis de la proporción sexual por grupo de talla, se registró que después de los 366,7 mm de LT en BLP y 398,9 mm LT en BM los machos están prácticamente ausentes, y que sólo en el grupo de talla menor (281,2 y 280,4 mm LT en BLP y en $\mathrm{BM}$, respectivamente) el número de hembras y machos es similar, sin embargo, en los restantes las hembras superan a los machos.

\section{LONGITUD MEDIA DE MADUREZ SEXUAL $\left(\mathrm{L}_{\mathbf{5 0} \%}\right)$}

La hembra $(\mathrm{H})$ y el macho $(\mathrm{M})$ de menor talla con gónadas maduras en BLP midieron 280 y $278 \mathrm{~mm}$ de LT respectivamente, y en BM 284 y $265 \mathrm{~mm}$ de LT, respectivamente. En ambas localidades se detectaron diferencias significativas en la $\mathrm{L}_{50 \%}$ entre sexos (ARSS: $\mathrm{F}=6,24, P<0,05$ en BLP y $\mathrm{F}=7,8, P<0,05$ en $\mathrm{BM})$, los machos maduraron en promedio a menor longitud que las hembras. En BLP se estimó una $\mathrm{L}_{50 \%}$ para machos de 268,9 mm de LT (intervalo de confianza al 95\%: 257,8-278,2 $\mathrm{mm})$ y $286,9 \mathrm{~mm}$ de LT $(279,4-292,2 \mathrm{~mm})$ para hembras, y en BM de $287,8 \mathrm{~mm}$ de LT $(268,4-294,4)$ para machos y $317,5 \mathrm{~mm}$ de LT $(312,2-324,6)$ para hembras (Fig. 8).

a)

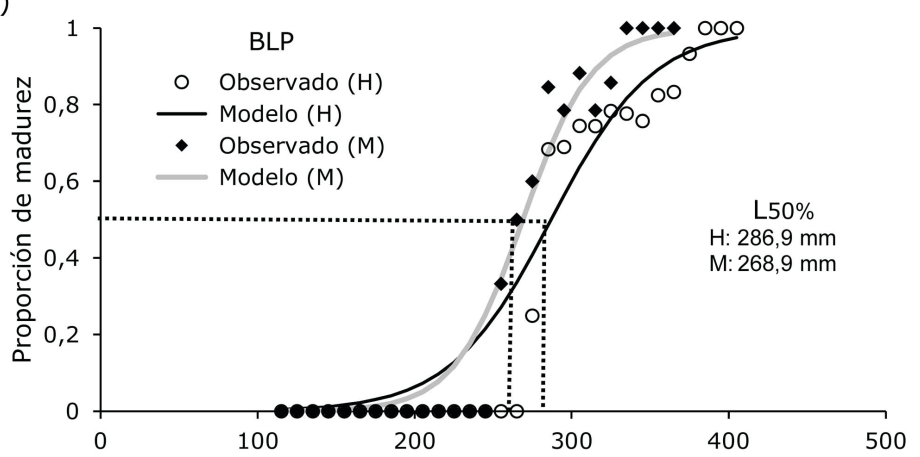

b)

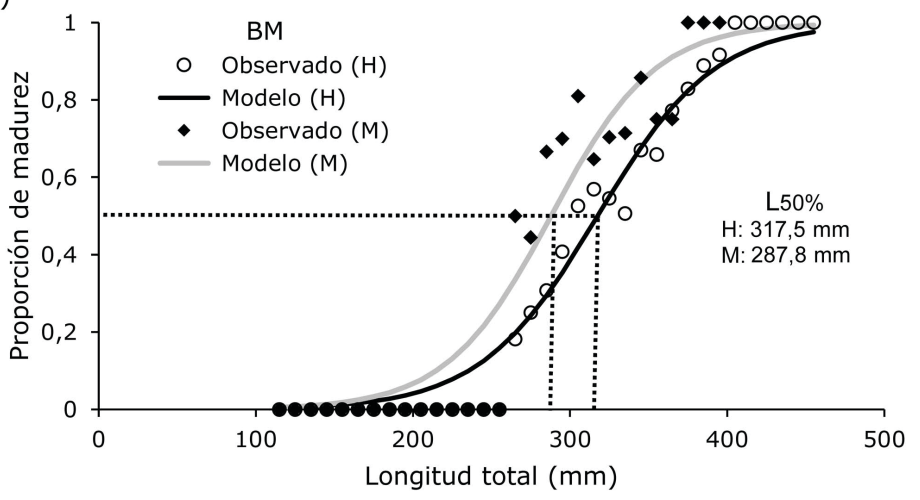

Figura 8. Longitud media de madurez sexual $\left(\mathrm{L}_{50 \%}\right)$ de hembras $(\mathrm{H})$ y machos $(\mathrm{M})$ de Mugil curema en a) Bahía de La Paz (BLP) y b) Bahía Magdalena (BM) / Average length of sexual maturity $\left(\mathrm{L}_{50 \%}\right.$ ) of females $(\mathrm{H})$ and males $(\mathrm{M})$ of Mugil curema in a) Bahía de La Paz (BLP) and b) Bahía Magdalena (BM) 


\section{Discusión}

El presente estudio es el primero en abordar aspectos sobre la estructura de tallas, relación peso-longitud y biología reproductiva de Mugil curema en ambas costas de Baja California Sur, a partir de información de organismos adultos y análisis histológico.

\section{ESTRUCTURA DE TALLAS}

El intervalo de tallas registrado en ambas localidades fue menos amplio al reportado para la misma especie en otros sitios del Pacífico mexicano (Gallardo-Cabello et al. 2005, Ruíz-Ramírez et al. 2017), y Golfo de México (Ibáñez \& Gallardo-Cabello 1996, Ibáñez \& GallardoCabello 2004). Sin embargo, en BM se registraron las mayores tallas para la especie (455 $\mathrm{mm}$ de LT) tanto en costas mexicanas (Ibáñez-Aguirre \& Gallardo-Cabello 1996, Ibáñez \& Gallardo-Cabello 2004, Gallardo-Cabello et al. 2005, Ruíz-Ramírez et al. 2017), como en costas del Atlántico suroccidental (Marin et al. 2003, Oliveira et al. 2011, Fernandez \& Dias 2013). La ausencia o poca representación de organismos juveniles en este trabajo, quizás sea un efecto asociado al tipo de redes empleadas en su captura (Vazzoler 1996), debido a que la luz de malla tiene gran influencia en la talla promedio de organismos capturados (Cabral-Solís 1999, Cabral-Solís et al. 2007); o bien, a la existencia de segregación por clase de talla en el área de captura (Ould-Mohamed-Vall 2004), ya que, generalmente los organismos de tallas menores permanecen en lagunas y esteros hasta alcanzar la talla adecuada para la reproducción (Ditty \& Shaw 1996). La diferencia en longitud y peso entre sexos (hembras más grandes y pesadas que machos) identificada en el presente trabajo, coincide con lo reportado en la mayoría de los estudios referentes a Mugil curema (Ibáñez \& GallardoCabello 1996, Lucano-Ramírez \& Michel-Morfín 1997, Gallardo-Cabello et al. 2005, Solomon \& Ramnarine 2007, Oliveira et al 2011, Ruíz-Ramírez et al. 2017). Esta estrategia se fundamenta en la capacidad de mejorar la condición corporal y la acumulación de reservas en lípidos con el tamaño y la edad (Lambert et al. 2003), lo que conduce a una mayor fecundidad (Nikolsky 1963, Wootton 1992).

\section{RELACIÓN PESO-LONGITUD}

En ambas localidades se identificó una relación alométrica negativa (2,4 en BLP y 2,6 en BM), los valores coinciden con el intervalo $(2,39$ a 3,11$)$ reportado para la especie en otras zonas del Pacífico mexicano y Golfo de México (Lucano-Ramírez \& Michel-Morfín 1997, Ibáñez 2015). Este resultado sugiere que las capturas en ambas localidades del presente estudio están compuestas principalmente por adultos jóvenes (Ibáñez 2015). En BM se presentó un valor mayor de $b$ que en BLP, dicha diferencia, aunque no significativa, quizás se relacione con el tamaño y peso promedio de los organismos en cada zona (BLP $<$ BM), ya que valores más bajos de b coinciden con especímenes de menor longitud, más jóvenes y menos robustos (Ibáñez 2015). También se ha reportado que diferencias en el valor de este parámetro puedan estar relacionadas con la latitud, ya que Mugil curema tiende a adaptarse mejor a los ambientes tropicales (Moore 1974). Tomando en cuenta lo sugerido por Ibáñez (2015), respecto a la influencia del muestreo en el índice de alometría, se tiene claro que en el presente trabajo faltó incluir a organismos juveniles dentro del análisis, para que las diferentes etapas de crecimiento fueran representadas. Sin embargo, este estudio proporciona información valiosa referente a la composición de la captura comercial.

\section{CARACTERÍSTICAS DE OVARIOS Y TESTÍCULOS}

Las características macroscópicas de los ovarios y testículos de $M$. curema fueron semejantes a las señaladas por la mayoría de los autores que han abordado la reproducción de esta especie (Lucano-Ramírez \& Michel-Morfín 1997, Marin et al. 2003, Ibáñez \& Gallardo-Cabello 2004, Solomon \& Ramnarine 2007, Albieri 2009, Cabral-Solís et al. 2010, Oliveira et al. 2011, Ibáñez \& Colín 2014, RuízRamírez et al. 2017). En el presente estudio, se identificó que en ambas localidades las hembras presentaron un desarrollo gonadal sincrónico por grupos (dos grupos de ovocitos en el ovario maduro, el primero en fase de crecimiento primario y el otro en post-vitelogénico), lo que sugiere un desove total de la especie. Patrón similar al reportado por Albieri et al. (2009) en Venezuela, Fernández \& Dias (2013) en Brasil, y Ruíz-Ramírez et al. (2017) en Jalisco, México. Sin embargo, este tipo de desarrollo no coincide con lo descrito por Solomon \& Ramnarine (2007) en Trinidad y Tobago, quienes identificaron hasta tres grupos de ovocitos en diferentes fases de desarrollo (perinucleolares, vitelogénesis inicial y post-vitelogénicos). A partir de ello los autores sugirieron que la liseta puede ser catalogada como un desovador múltiple, y que teniendo en cuenta la capacidad adaptativa que presentan las especies al estar sometidas a distintos gradientes ambientales (Wootton 1992), tales diferencias podrían ser consecuencia de que se trate de poblaciones completamente aisladas, cuyas tácticas reproductivas se definen a partir de las particularidades de cada región (Pacífico mexicano, Caribe y Suroeste del Atlántico).

La descripción microscópica del desarrollo gonadal en machos implicó un análisis más detallado de la estructura. Esto debido a factores como la disminución del tamaño de las células conforme avanza la maduración, la presencia simultánea en la misma gónada de células en más de dos fases de desarrollo, células maduras en estadios que aún no son aptos para el desove (fase de desarrollo tardío) y la capacidad de los machos de mantenerse en condiciones de desove durante gran parte de la temporada reproductiva 
(Brown-Peterson et al. 2011). Sin embargo, fue posible clasificar a todos los machos analizados y detectar una sincronía con el proceso de maduración en hembras, tal como señalan Oliveira et al. (2011), Fernandez \& Dias (2013) y Ruiz-Ramírez et al. (2017). En algunos casos, después del periodo de máxima actividad reproductiva, se identificaron machos con gónadas en fase de regresión, sin embargo, no fueron incluidos en la categoría de capacidad de desove, debido a que se consideraron como organismos en receso reproductivo.

\section{Ciclo Reproductivo}

Generalmente, los peces se reproducen cuando las condiciones ambientales incrementan la probabilidad de supervivencia de las larvas, evitando periodos de baja disponibilidad de alimento y por consecuencia un lento crecimiento (Chellappa et al. 2010), en este sentido, es probable que, en el presente estudio, las diferencias en la periodicidad reproductiva de la liseta entre localidades puedan estar relacionadas con la variabilidad ambiental (Albieri et al. 2010). En zonas subtropicales, como es el caso de BLP y BM, los cambios en temperatura y el fotoperiodo juegan un papel preponderante en el ciclo de vida de los peces, principalmente en la reproducción (Estrada-Godínez et al. 2014). Por ejemplo, ReyesSalinas et al. (2003) reportan una tendencia estacional en la productividad primaria (PP) en BLP, con máximos en marzo (16 $\left.\mathrm{mg} \mathrm{C} \mathrm{m}^{-3} \mathrm{~h}^{-1}\right)$ cuando se incrementan el fotoperiodo y la TSM y octubre $\left(5 \mathrm{mg} \mathrm{C} \mathrm{m}^{-3} \mathrm{~h}^{-1}\right)$ diminución del fotoperiodo y de la TSM. Eventos que coinciden con los dos picos reproductivos observados en este estudio, lo que puede sugerir una posible sincronización del desarrollo gametogénico con un intervalo similar de TSM entre 23 y $26{ }^{\circ} \mathrm{C}$ (Reyes-Salinas et al. 2003) y el desove con el periodo de alta PP. Por otro lado, es posible que la liseta sincronice su periodo de reposo reproductivo con los meses más cálidos del año (agosto y septiembre) con TSM promedio entre 28 y $31^{\circ} \mathrm{C}$, y de menor PP $(2 \mathrm{mg} \mathrm{C}$ $\mathrm{m}^{-3} \mathrm{~h}^{-1}$ ) (Reyes-Salinas et al. 2003), ya que, durante este periodo se registró la menor proporción de organismos maduros durante los 4 años de muestreo (8\%). Es posible inferir una relación similar en BM, cuyo inicio y fin del periodo reproductivo coincide con los meses en los que se registra la menor y mayor TSM (marzo-abril con $17,2^{\circ} \mathrm{C}$ y agosto-septiembre con $26^{\circ} \mathrm{C}$ ) (Sánchez-Montante et al. 2007). Los meses con mayor proporción de organismos maduros en BM (mayo-julio) coinciden con un intervalo de TSM de 19 a $23{ }^{\circ} \mathrm{C}$, además de una mayor PP y acumulación de materia orgánica. En contraste, los meses en los que existe un reposo reproductivo coinciden con las temperaturas más altas del año y menor productividad primaria (Palomares-García \& Gómez-Gutiérrez 1996). Otros estudios referentes a la liseta también han sugerido sincronía entre el periodo de desove y algunas variables ambientales, como la estación húmeda o temporada de lluvias (Yáñez-Arancibia 1976, Albieri et al. 2009), los cambios en la TSM (Ibáñez \& Gutiérrez-Benítez 2004), cambios en el fotoperiodo y productividad primaria (Solomon \& Ramnarine 2007), y eventos de surgencias (Marin et al. 2003).

\section{ÍNDICE GONADOSOMÁTICO, ÍNDICE HEPATOSOMÁTICO Y FACTOR DE CONDICIÓN}

El FC y el IHS se han utilizado para evaluar la condición fisiológica de los peces y relacionarla con el IGS (Albieri et al. 2009), bajo el fundamento de que los organismos emplean la energía hepática y grasa corporal durante el proceso de gametogénesis (Kanak \& Tachihara 2008). En este sentido, se sugiere que en ambas localidades estudiadas la liseta presenta una sincronía entre sexos en el proceso de maduración y desove (partición del IGS similar entre hembras y machos), al igual que la condición corporal (comportamiento temporal cercano en el IHS y FC). También, fue posible identificar una asociación positiva no significativa entre el IGS y el IHS, esto podría sugerir que existe una relación entre el incremento en masa del hígado y la temporada reproductiva, ya que este órgano cumple un papel importante durante la acumulación de lípidos y la síntesis de vitelogénina, por lo que tiende a incrementar el número y el tamaño de los hepatocitos (Saborido-Rey 2008). En el caso del FC, en ambas localidades se detectó una tendencia similar con respecto a la del IGS, sin embargo, esta no fue significativa, lo cual podría sugerir que el proceso de maduración tiene poca o nula influencia en la condición corporal (composición muscular) en $M$. curema, al menos en BLP y BM, y que quizás la energía necesaria para garantizar el éxito reproductivo provenga en mayor proporción de fuentes alternas, como la grasa visceral acumulada (Kanak \& Tachihara 2008). Estos resultados contrastan con lo reportado por Cabral-Solís et al. (2010) y Ruíz-Ramírez et al. (2017) para M. curema en costas de Colima y Jalisco, en el Pacífico mexicano, respectivamente, ya que estos autores observaron incrementos del FC en los meses que ocurrieron desoves.

\section{Proporción SEXUAL}

Tanto en BLP como en BM durante la mayor parte del periodo de estudio la proporción sexual fue distinta de lo esperado teóricamente (1H:1M) (Nikolsky 1963), con un claro dominio en el número de hembras sobre el de machos. Estos resultados sugieren que durante casi todo el año gran parte de la población explotada dentro de ambas bahías está conformada por hembras (>70\%). Lo que coincide con la mayoría de los trabajos sobre Mugil curema efectuados en el Pacífico mexicano (LucanoRamírez \& Michel-Morfín 1997, Cabral-Solís et al. 2010, Ruíz-Ramírez et al. 2017), como en el Golfo de México 
(Ibáñez \& Gallardo-Cabello 2004, Ibáñez \& Colín 2014) y en las costas de Brasil (Albieri et al. 2009, 2010; Fernández \& Días 2013). A diferencia del estudio de Oliveira et al. (2011) realizado en la costa noroeste de Brasil, en donde se obtuvo una proporción igual a la esperada (1H:1:M). Estas diferencias entre la cantidad de hembras y machos, puede deberse a una segregación por clase de edad y sexo, ya que, en especies del género Mugil, generalmente los machos permanecen la mayor parte del tiempo en zonas alejadas de la costa (Ould-Mohamed-Vall 2004), o bien, a causas como diferencias en la mortalidad, el crecimiento, la longevidad, la actividad sexual, las tasas de migración, zonas de crianza y desove (Wootton 1992).

\section{LONGITUD MEDIA DE MADUREZ SEXUAL}

Un aspecto de gran interés en la ecología de la reproducción es el hecho de que la edad y talla media de madurez sexual puede variar dentro de una misma especie, ya sea espacial o temporalmente (Saborido-Rey 2008). En este sentido, el presente estudio detectó diferencias significativas en el valor de $\mathrm{L}_{50 \%}$ entre localidades y sexos, en BM la liseta madura a mayores tallas que en BLP, y en ambas localidades las hembras maduran a una talla mayor que los machos (aproximadamente de 20 a $30 \mathrm{~mm}$ de diferencia). Resultado que se ha reportado anteriormente para la especie (Ruíz-Ramírez et al. 2017) y otros mugílidos (Kendall \& Gray 2008), sin embargo, también se ha observado lo contrario (Ibáñez \& Gallardo-Cabello 2004, Oliveira et al. 2011). McDonough et al. (2005), argumentan que tal variación en la $\mathrm{L}_{50 \%}$ está condicionada por las características particulares de cada especie e incluso de cada población, por tanto, en el caso de especies detritívoras, de talla grande y vida relativamente longeva como la liseta, la madurez tiende a alcanzarse a tallas y edades mayores. En ambas localidades del presente estudio los valores de $\mathrm{L}_{50 \%}$ resultaron mayores a los reportados para esta especie en costas de México y Brasil (Tabla 2). La característica de una maduración relativamente tardía puede tener algunas ventajas de supervivencia, por ejemplo, en las hembras de algunos mugílidos, la fecundidad y calidad de los ovocitos están directamente relacionadas con el tamaño corporal (Ibáñez \& Colín 2014). Por lo tanto, si la talla de madurez sexual es mayor en esta zona, es posible que la fecundidad y la calidad de los ovocitos también lo sean (Lowerre-Barbieri et al. 2011). Es importante tener en cuenta que, en ambas localidades del presente estudio, las tallas promedio de captura (323 y $330 \mathrm{~mm}$ LT en BLP y BM, respectivamente) fueron cercanas a la $\mathrm{L}_{50 \%}$, por tal motivo, se recomienda tener precaución en el tamaño de luz de malla empleado para la captura de liseta en ambas costas de BCS, de manera que la mayoría de los organismos hayan tenido la oportunidad de reproducirse al menos una vez antes de ser capturados, tal como proponen CabralSolís et al. (2007) para la pesca artesanal en Laguna de Cuyutlán, Colima, México.

\section{Agradecimientos}

Este estudio fue financiado por el Instituto Politécnico Nacional (IPN). LSC recibió una beca de posgrado de CONACyT y del Programa de Estímulo Institucional de Formación de Investigadores del IPN. CQV y FAGD son miembros de la Comisión de Operación y Fomento de Actividades Académicas de IPN, Estímulos al Desempeño de los Investigadores de IPN y Sistema Nacional de Investigadores-CONACYT. Agradecemos a todos los involucrados en la recolección y procesamiento del material biológico para este estudio. Además, agradecemos a tres revisores anónimos por sus comentarios constructivos que mejoraron el contenido y la presentación de nuestro estudio.

Tabla 2. Longitud media de madurez sexual $\left(\mathrm{L}_{50 \%}\right)$ de Mugil curema estimada por diversos autores / Average sexual maturity length $\left(\mathrm{L}_{50 \%}\right)$ for $M u g i l$ curema estimated by various authors

\begin{tabular}{llccc}
\hline \multirow{2}{*}{ Referencias } & \multicolumn{1}{c}{ Área de estudio } & \multicolumn{2}{c}{ L50\% $(\mathrm{mm})$} \\
\cline { 3 - 5 } & & Ambos sexos & Hembras & Machos \\
\hline Lucano-Ramírez \& Michel-Morfín (1997) & Jalisco & - & $240^{1}$ & $220^{1}$ \\
Cabral-Solís (1999) & Colima & $271-280$ & - & - \\
Cabral-Solís et al. (2010) & Colima & - & 255 & 270 \\
Oliveira et al. (2011) & Brasil & 255 & 240 & 264 \\
Fernández \& Díaz (2013) & Brasil & 248,6 & - & - \\
Ruíz-Ramírez et al. (2017) & Jalisco & - & 245 & 217 \\
Presente estudio & Bahía de La Paz, BCS & - & 286,9 & 268,94 \\
& Bahía Magdalena, BCS & - & 317,5 & 387,8 \\
\hline
\end{tabular}

${ }^{1}$ Talla mínima de reproducción 


\section{LITERATURA CITADA}

AEP. 2017. Anuario estadístico pesquero, 300 pp. Secretaría de Agricultura, Ganadería y Desarrollo Rural, Pesca y Alimentación, Comisión Nacional de Pesca, Mazatlán, Sinaloa. <https://www.gob.mx/conapesca/ documentos/ anuario-estadístico-de-acuacultura-y-pesca>

Albieri RJF, G Araújo \& TP Ribeiro. 2009. Gonadal development and spawning season of white mullet Mugil curema (Mugilidae) in a tropical bay. Journal of Applied Ichthyology 26(1): 105-109.

Albieri RJF, G Araújo \& W Uehara. 2010. Differences in reproductive strategies between two co-occurring mullets Mugil curema Valenciennes 1836 and Mugil liza Valenciennes 1836 (Mugilidae) in a tropical bay. Tropical Zoology 23(1): 51-62.

Bernal G, P Ripa \& JC Huerguera. 2001. Variabilidad oceanográfica y climática en el Bajo Golfo de California: Influencias del Trópico y Pacífico Norte. Ciencias Marinas 27(4): 595-617.

Blaber SJM. 1997. Fish and fisheries of tropical estuaries, 367 pp. Chapman \& Hall, London.

Brown-Peterson NJ, DM Wyanski, F Saborido-Rey, BJ Macewicz \& SK Lowerre-Barbieri. 2011. A standardized terminology for describing reproductive development in fishes. Marine and Coastal Fisheries: Dynamics, Management, and Ecosystem Science 3(1): 52-70.

Cabral-Solís EG. 1999. Estudio sobre el crecimiento y aspectos reproductivos de la lebrancha Mugil curema Cuvier y Valenciennes, 1836, en la laguna de Cuyutlán, Colima. Tesis de Maestría, Universidad de Colima, Colima, $91 \mathrm{pp}$.

Cabral-Solís EG, E Espino-Barr, M Gallardo-Cabello \& AL Ibáñez-Aguirre. 2007. Fishing impact on Mugil curema stock of multi-species gill net fishery in a tropical lagoon, Colima, Mexico. Journal of the Fisheries and Aquatic Science 2(3): 235-242.

Cabral-Solís EG, M Gallardo-Cabello, E Espino-Barr \& AL Ibáñez. 2010. Reproduction of Mugil curema (Pisces: Mugilidae) from the Cuyutlán lagoon, in the Pacific coast of México. Avances en Investigación Agropecuaria 14(3): 19-32.

Castro-Aguirre JL. 1978. Catálogo sistemático de los peces marinos que penetran a las aguas continentales de México con aspectos zoogeográficos y ecológicos. Instituto Nacional de Pesca, Serie Científica 19: 1-298.

Chellappa S, JT Lima, A Araújo \& NT Chellappa. 2010. Ovarian development and spawning of Serra Spanish mackerel in coastal waters of Northeastern Brazil. Brazilian Journal of Biology 70(2): 451-456.

Ditty JG \& RF Shaw. 1996. Spatial and temporal distribution of larval Striped Mullet (Mugil cephalus) and White Mullet (M. curema) (Family: Mugilidae) in the northern Gulf of Mexico, with notes on Mountain Mullet, Agnostomus monticola. Bulletin of Marine Science 59(2): 271-288.

Enberg K, C Jørgensen, ES Dunlop, Ø Varpe, DS Boukal, L Baulier, S Eliassen \& M Heino. 2012. Fishing-induced evolution of growth: concepts, mechanisms and the empirical evidence. Marine Ecology 33(1): 1-25.
Estrada-Godínez JA, M Maldonado-García, V GraciaLópez, M Carrillo, R Rebollar-Prudente \& M Spanopoulos-Zarco. 2014. Efecto del fotoperiodo y la temperatura sobre la composición bioquímica en reproductores silvestres de cabrilla sardinera, Mycteroperca rosacea (Streets, 1877). Latin American Journal of Aquatic Research 42(1): 85-96.

Fernandez WS \& JF Dias. 2013. Aspects of the reproduction of Mugil curema Valenciennes, 1836 in two coastal systems in the southeastern Brazil. Tropical Zoology 26(1): 15-32.

Funes-Rodríguez R, J Gómez-Gutiérrez \& R PalomaresGarcía. 2007. Área de estudio: complejo lagunar de Bahía Magdalena-Almejas. En: Funes-Rodríguez R, J GómezGutiérrez \& R Palomares-García (eds). Estudios ecológicos en Bahía Magdalena, pp. 21-28. CICIMAR-IPN, La Paz.

Gallardo-Cabello M, E Cabral-Solís, E Espino-Barr \& AL Ibáñez-Aguirre. 2005. Growth analysis of white mullet Mugil curema (Valenciennes, 1836) (Pisces: Mugilidae) in the Cuyutlán Lagoon, Colima, México. Hidrobiológica 15(3): 321-325.

Gherard KE, BE Erisman, O Aburto-Oropeza, K Rowell \& LG Allen. 2013. Fishery-dependent estimates of growth, development, and reproduction in Gulf Corvina (Cynoscion othonopterus). Bulletin of the Southern California Academy of Sciences 112(1): 1-18.

Harrison IJ. 1995. Mugilidae. Lisas. En: Fischer W, F Krupp, W Schneider, C Sommer, KE Carpenter \& V Niem (eds). Guía FAO para identificación de especies para los fines de la pesca. Pacífico Centro Oriental 3: 1293-1298. FAO, Roma.

Ibáñez AL. 2015. Geographic differences and annual stability in length-weight relationships of fish mullets (Pisces: Mugilidae). Hidrobiológica 25(1): 146-150.

Ibáñez AL \& A Colín. 2014. Reproductive biology of Mugil curema and Mugil cephalus from western Gulf of Mexico Waters. Bulletin of Marine Science 90(4): 941-952.

Ibáñez AL \& M Gallardo-Cabello. 1996. Total and natural mortality of Mugil cephalus and M. curema (Pisces: Mugilidae), in Tamiahua Lagoon, Veracruz. I. Selectivity. Hidrobiológica 6(1): 9-16.

Ibáñez AL \& M Gallardo-Cabello. 2004. Reproduction of Mugil cephalus and M. curema (Pisces: Mugilidae) from coastal lagoon in the Gulf of Mexico. Bulletin of Marine Science 75(1): 37-49.

Ibáñez AL \& M Gallardo-Cabello. 2005. Identification of two Mugilidae species, Mugil cephalus and M. curema (Pisces: Mugilidae), using the ctenii of their scales. Bulletin of Marine Science 77(2): 305-307.

Ibáñez AL \& O Gutiérrez-Benítez. 2004. Climatic Parameters and spawning migrations of Mugil cephalus and M. curema in the Northwestern area of the Gulf of Mexico. Journal of Fish Biology 65(3): 822-831.

Ibáñez-Aguirre AL \& M Gallardo-Cabello. 1996. Age determination of the grey mullet Mugil cephalus L. and the white mullet M. curema V. (Pisces: Mugilidae) in Tamiahua lagoon, Veracruz. Ciencias Marinas 22(3): 329-345.

Jacob-Cervantes ML \& H Aguirre-Villaseñor. 2014. Inferencia multimodelo y selección de modelos aplicados a la determinación de L50 para la sardina crinuda Opisthonema libertate del sur del Golfo de California. Ciencia Pesquera 22(1): 61-68. 
Kanak MK \& K Tachihara. 2008. Reproductive biology of common silver biddy Gerres oyena in Okinawa Island of southern Japan. Fisheries Science 74(2): 265-275.

Kendall BW \& CA Gray. 2008. Reproductive biology of two co-occurring mugilids, Liza argentea and Myxus elongates, in southeastern Australia. Journal of Fish Biology 73(4): 963-979.

Kutner MH, CJ Nachtsheim, J Neter \& W Li. 2004. Applied linear statistical models, 1396 pp. McGraw-Hill/Irwin, New York.

Lambert Y, NA Yaragina, G Kraus, G Marteinsdottir \& PJ Wright. 2003. Using environmental and biological indices as proxies for egg and larval production of marine fish. Journal of Northwest Atlantic Fishery Science 33: 115-159.

Lowerre-Barbieri S, N Brown-Peterson, H Murua, J Tomkiewicz, D Wyanski \& F Saborido-Rey. 2011. Emerging issues and methodological advances in fisheries reproductive biology. Marine and Coastal Fisheries Dynamics, Management, and Ecosystem Science 3(1): 32-51.

Lucano-Ramírez G \& JE Michel-Morfin. 1997. Ciclo reproductivo y aspectos poblacionales de Mugil curema Valenciennes, 1836 (Pisces: Mugilidae) en la laguna costera Agua Dulce, Jalisco, México. Oceanología 1(13): 105-115.

Lucano-Ramírez G, S Ruíz-Ramírez, G González-Sansón \& BP Ceballos-Vázquez. 2014. Biología reproductiva del pargo alazán, Lutjanus argentiventris (Pisces, Lutjanidae), en el Pacífico central mexicano. Ciencias Marinas 40(1): 33-44.

Lysack W. 1980. Lake Winnipeg fish stock assessment program, 67 pp. Manitoba Department of Natural Resources Research Report 80-30: 1-118.

Marin EBJ, A Quintero, D Bussière \& JJ Dodson. 2003. Reproduction and recruitment of white mullet (Mugil curema) to a tropical lagoon (Margarita Island, Venezuela) as revealed by otolith microstructure. Fishery Bulletin 101(4): 809-821.

McDonough CJ, WA Roumillat \& CA Wenner. 2005. Sexual differentiation and gonad development in striped mullet (Mugil cephalus L.) from South Carolina estuaries. Fishery Bulletin 103(4): 601-619.

Moore RH. 1974. General ecology, distribution and relative abundance of Mugil cephalus and Mugil curema on the South Texas coast. Contributions in Marine Science 18: 241-255.

Nikolsky GV. 1963. The ecology of fishes, $352 \mathrm{pp}$. Academic Press, New York.

Oliveira MF, EFC Costa, FAM Freire, JEL Oliveira \& AC Luchiari. 2011. Some aspects of the biology of white mullet, Mugil curema (Osteichthyes, Mugilidae), in the northeastern region, Brazil. Pan-American Journal and Aquatic Sciences 6(2): 138-147.

Ould-Mohamed-Vall M. 2004. Etude de la dynamique des systèmes d'exploitation et de l'écobiologie de la reproduction de trois Mugilidae: Mugil cephalus (Linnaeus, 1758), Liza aurata (Perugia, 1892) et Mugil capurrii (Risso, 1810), analyse de leurs stratégies d'occupations des secteurs littoraux mauritaniens et de leurs possibilités d'aménagement. Tesis Doctoral, University Nice-Sophia, Antipolis, $146 \mathrm{pp}$.
Palomares-García RJ \& J Gómez-Gutiérrez. 1996. Copepod community structure at Bahía Magdalena, México during El Niño 1983-1984. Estuarine, Coastal and Shelf Science 43(1): 583-595.

Pauly D \& J Munro. 1984. Once more on the comparison of growth in fish and invertebrates. Fishbyte, The WorldFish Center 2(1): 1-21.

Polacheck T, R Hilborn \& AE Punt. 1993. Fitting surplus production models: Comparing methods and measuring uncertainty. Canadian Journal of Fisheries and Aquatic Sciences 50(12): 2597-2607.

Present TMC \& DO Conover. 1992. Physiological basis of latitudinal growth differences in Menidia menidia: variation in consumption or efficiency? Functional Ecology 6(1): 23-31.

Reyes-Salinas AR, R Cervantes-Duarte, A Morales-Pérez \& JE Valdez-Holguín. 2003. Variabilidad estacional de la productividad primaria y su relación con la estratificación vertical en la Bahía de la Paz, B.C.S. Hidrobiológica 13(2): 103-110.

Rodríguez-Gutiérrez M. 1992. Técnicas de evaluación cuantitativas de la madurez gonádica en peces, $79 \mathrm{pp}$. AGT Editor, México.

Ruiz-Ramírez S, EG Molina-Arenas, G LucanoRamírez, C Aguilar-Betancourt, JR Flores-Ortega, D Kosonoy-Aceves \& G González-Sansón. 2017. Aspectos reproductivos de la lisa Mugil curema (Mugiliformes: Mugilidae) en la laguna costera de Barra de Navidad, Jalisco, México. Latin American Journal of Aquatic Research 45(2): 443-456.

Saborido-Rey F. 2008. Ecología de la reproducción y potencial reproductivo en las poblaciones de peces marinos, $71 \mathrm{pp}$. Instituto de Investigaciones Marinas (CSIC), Universidad de Vigo, Vigo.

Sánchez-Cárdenas R, BP Ceballos-Vázquez, M ArellanoMartínez, MC Valdez-Pineda \& RE Morán-Angulo. 2007. Reproductive aspects of Sphoeroides annulatus (Jenyns, 1842) (Tetraodontiformes, Tetraodontidae) inhabiting the Mazatlan coast, Sinaloa, Mexico. Revista de Biología Marina y Oceanografía 42(3): 385-392.

Sánchez-Montante O, O Zaitsev \& M Saldivar-Reyes. 2007. Condiciones hidrofísicas en el sistema lagunar Bahía Magdalena-Almejas. En: Funes-Rodríguez R, J GómezGutiérrez \& R Palomares-García (eds). Área de estudio: complejo lagunar de Bahía Magdalena-Almejas. Estudios ecológicos en Bahía Magdalena, pp. 34-61. CICIMARIPN, La Paz.

Solomon NF \& IW Ramnarine. 2007. Reproductive biology of white mullet, Mugil curema Valenciennes in the Southern Caribbean. Fisheries Research 88(1-3): 133-138.

Stearns SC. 1980. A new view of life-history evolution. Oikos 35(2): 266-281.

Trape S, JD Durand, F Guilhaumon, L Vigliola \& J Panfili. 2009. Recruitment patterns of young-of-the-year mugilid fishes in a West African estuary impacted by climate change. Estuarine Coastal and Shelf Science 85(3): 357367. 
Vasconcelos J, S Sánchez \& L Schultz. 1996. La pesquería de lisa. En: Sánchez-Palafox A, DF Fuentes-Castellanos \& S García-Real-Peñaloza (eds). Pesquerías relevantes de México. 33 Aniversario del INP. Tomo 2: 581-594, Secretaría de Medio Ambiente, Recursos Naturales y Pesca, Instituto Nacional de Pesca, Ciudad de México.

Vazzoler AEA de M. 1996. Biología e reproducao de peixes teleósteos: Teoria e practica, 169 pp. EDUEN, Sao Paulo.

Wootton RJ. 1992. Constraints in the evolution of fish life histories. Netherlands Journal of Zoology 42(2-3): 291-303.
Yáñez-Arancibia A. 1976. Observaciones sobre Mugil curema Valenciennes en áreas naturales de crianza, México. Alimentación, crecimiento, madurez y relaciones ecológicas. Anales del Instituto de Ciencias del Mar y Limnología, Universidad Nacional Autónoma de México 3: 92-124.

Zar JH. 2010. Biostatistical analysis, 994 pp. Pearson/Prentice Hall, Upper Saddle River.

Recibido el 8 de abril de 2020 y aceptado el 16 de marzo de 2021 